Yaşar Tuncer KAVUT

A. Esen ÇELEN

Ege Üniversitesi, Ziraat Fakültesi, Tarla Bitkileri Bölümü, 35100, İzmir / Türkiye

sorumlu yazar: tuncer.kavut@ege.edu.tr

Anahtar Sözcükler:

Yembezelyesi, tohum verimi, bezelye çeşitleri, sıra arası mesafesi

Key Words:

Forage pea, seed yield, pea cultivars, row spacing

\section{Kimi Yembezelyesi Çeşitlerinde (Pisum arvense L.) Sıra Arası Mesafelerinin Tohum Verimi ile Bazı Verim Özelliklerine Etkisi Üzerinde Bir Araştırma}

\author{
An Investigation on the Effect of Row Spacings on the Seed \\ Yield and Related Characteristics of Some Forage Pea (Pisum \\ arvense L.) Cultivars
}

Alınış (Received): 19.09.2016 Kabul tarihi (Accepted): 31.10.2016

\section{ÖZET}

2013 ve 2014 yıllarında Ege Üniversitesi Ziraat Fakültesi Tarla Bitkileri 2 Bölümü deneme tarlalarında yürütülen bu araştırmada, iki farklı sıra arası mesafesinde $(20 \mathrm{~cm}$ ve $40 \mathrm{~cm}$ ) üç farklı yembezelyesi çeşidinin (Kirazlı, Töre ve Taşkent) tohum verimleri ve bununla ilgili özellikleri incelenmiştir. Araştırmada, metrekaredeki bitki sayısı, bitkide bakla sayısı, baklada tane sayısı, bin dane ağırlığı ve tohum verimi gibi karakterler ele alınmıştır. Hasattaki bitki sayısı, bitkide bakla sayısı ve baklada tane sayısı sıra arası uzaklıktan önemli ölçüde etkilenmiştir. İki yıllık deneme sonuçlarına göre, en yüksek birim alan tane verimi $309.8 \mathrm{~kg} / \mathrm{da}$ ile Kirazlı çeşidinden alınırken, en düşük birim alan tane verimi ise $95.6 \mathrm{~kg} / \mathrm{da}$ ile Töre çeşidinden elde edilmiştir.

\section{GíRiş}

Geniş bir adaptasyon yeteneğine sahip olması yanında, verim ve kalite özellikleri yönünden bölge koşullarında özellikle kışlık ikinci ürün olarak kullanılan yembezelyesi, toprağa $5-15 \mathrm{~kg} / \mathrm{da}$ arasında azot bağlaması ve kendisinden sonra gelen bitkiye temiz bir anız bırakması nedeniyle önemli bir serin iklim bitkisidir (Uzun ve ark., 2012). 2014 yılı TUiK verilerine göre; Türkiye'de 37395 da alanda 70422 ton yembezelyesi yeşil ot olarak üretilirken, bu durum Ege bölgesinde 143 da alan arazide 380 ton olarak gerçekleşmiş ve ortalama verim de $2657 \mathrm{~kg} / \mathrm{da}$ olarak kaydedilmiştir (TUiK, 2015).

Yembezelyesinde verim artışını sağlayan kültürel önlemlerden biri de uygun sıklığı sağlayan sıra aralığının seçilip uygulanmasıdır. Sıra aralığı bir başka deyişle ekim sıklığı çeşitlere göre değiştiği gibi, ekolojik bölgelere göre de farklılıklar gösterebilmektedir. Bu nedenle, değişik bölgelerde yapılacak ekim sıklığı ya da sıra aralığı çalışmalarından yararlı sonuçlar elde edilebilmektedir. Bu sonuçların uygulamaya konulmasıyla kültürel uygulamaların kolaylaştırılması ve 
verim artışının da sağlanması beklenmelidir (Toğay ve ark., 2006).

Bozoğlu vd. (2004); sıra arası mesafelerinin artması ile yembezelyesi çeşitlerinde bakla ve tane sayısı değerleri ile tane veriminin arttığını ifade etmişlerdir. Uzun vd. (2011); farklı yembezelyesi çeşitleri ile sürdürdükleri çalışmada bitkide bakla sayısının 8.711.4 adet, baklada tane sayısının 4.3-5.0 adet, tane veriminin de 257-362 kg/da arasında değiştiğini bildirmişlerdir. Alan ve Geren (2012); yembezelyesinde verimin ortalama $143 \mathrm{~kg} /$ da olduğunu bildirmişlerdir. Tan vd. (2012); bitkide bakla sayısının 12.4 adet, baklada tane sayısının 4.5 adet, bin tane ağırlığının $91.9 \mathrm{~g}$ ve tane veriminin de $173 \mathrm{~kg} / \mathrm{da}$ olduğunu kaydetmişlerdir.

\section{MATERYAL ve YÖNTEM}

Araştırma, 2013-2014 ve 2014-2015 bitki yetiştirme mevsimlerinde, Ege Üniversitesi Ziraat Fakültesi Tarla Bitkileri deneme tarlalarında yürütülmüştür. Deneme yerinin 2014 ve 2015 yıllarına ait ortalama sıcaklık ile toplam yağış değerleri Çizelge 1'de sunulmuştur (Anonim, 2015). Araştırma yeri toprağı, 0-20 cm derinlikte milli-kil bünyeye sahip olup, $\mathrm{pH}$ : 7.8, organik madde \% 1.13, kireç \% 21.52, azot $\% 0.11$, fosfor 40 ppm, potasyum 400 ppm değerlerine sahiptir. Gerek iklim ve gerekse toprak özellikleri, araştırmaya konu olan yembitkileri tarımı açısından kısıtlayıcı herhangi bir etki göstermemektedir. Araştırmada bitkisel materyal olarak Kirazlı, Taşkent ve Töre yembezelyesi çeşitleri kullanılmış, tarla denemesi faktöriyel tesadüf blokları deneme desenine göre 3 tekerrürlü olarak kurulmuştur. Ekim, her iki deneme yılında da Kasım ayı içerisinde, markör ile açılan çiziler içerisine el ile yapılmıştır. İki farklı sıra arası mesafesinde $20 \mathrm{~cm}$ ve $40 \mathrm{~cm}$ olarak kurulan denemede, parsel boyutları $3.0 \mathrm{~m} \times 2.4 \mathrm{~m}$ olmuştur. Ekimden önce dekara $3 \mathrm{~kg} \mathrm{~N}$ (Amonyum Sülfat gübresi) uygulanmıştır (Uzun vd., 2012). Hasatta, parsel başlarından $0.5 \mathrm{~m}$ ve parsel yanlarından da birer sıra kenar tesiri olarak atıldıktan sonra bütün işlemler geriye kalan alan üzerinde yapılmıştır. Denemede, çiçeklenme gün sayısı, olgunlaşma gün sayısı, yan dal sayısı, bitkide bakla sayısı, baklada tane sayısı, biyolojik verim, tohum verimi ve bin dane ağırlığı gibi karakterler incelenmiştir. Çizelgelerde ilgili karakterlere ait araştırma sonuçları sunulmuş ve istatistiksel olarak analizleri, TOTEM-STAT hazır paket programı kullanılarak yapılmıştır (Açıkgöz, 1993). Önemli görülen uygulamalar arasındaki farklılıklar LSD (\% 5)'e göre kontrol edilmiştir.

Çizelge 1. Araştırma Yerine Ait İklim Verileri

Table 1. Some meteorological data for experimental area

\begin{tabular}{lcccccc}
\hline \multirow{2}{*}{ Aylar } & \multicolumn{3}{c}{ Ortalama Sıcaklık $\left({ }^{\circ} \mathbf{C}\right)$} & \multicolumn{3}{c}{ Toplam Yağış (mm) } \\
\cline { 2 - 7 } & $\mathbf{2 0 1 3 - 2 0 1 4}$ & $\mathbf{2 0 1 4 - 2 0 1 5}$ & Çok yıllık & $\mathbf{2 0 1 3 - 2 0 1 4}$ & $\mathbf{2 0 1 4 - 2 0 1 5}$ & Çok yıllık \\
\hline Kasım & 15.0 & 13.8 & 14.1 & 129.1 & 31.2 & 97.3 \\
Aralık & 8.5 & 11.8 & 10.6 & 9.1 & 249.3 & 147.5 \\
Ocak & 11.7 & 8.4 & 8.8 & 149.9 & 175.0 & 118.6 \\
Şubat & 11.7 & 8.9 & 9.4 & 14.8 & 100.9 & 103.8 \\
Mart & 11.7 & 11.0 & 11.7 & 106.4 & 91.5 & 75.3 \\
Nisan & 16.7 & 14.2 & 15.9 & 132.2 & 31.4 & 48.3 \\
Mayıs & 20.5 & 21.3 & 20.9 & 15.3 & 29.0 & 26.9 \\
\hline & 12.1 & 12.8 & 13.1 & 556.8 & 708.3 & 617.7 \\
\hline
\end{tabular}

Çizelge 2. Farklı Sıra Arası Mesafelerinde Yetiştirilen Bazı Yembezelyesi Çeşitlerinin Olgunlaşma Gün Sayıları (gün) Table 2. Number of days to maturity of some forage pea cultivars grown at different row spacings (day)

\begin{tabular}{|c|c|c|c|c|c|c|c|c|c|c|}
\hline & \multicolumn{4}{|c|}{2013} & \multicolumn{3}{|c|}{2014} & \multicolumn{3}{|c|}{ 2013-2014 } \\
\hline Çeşitler & & cm & $40 \mathrm{~cm}$ & Ort. & $20 \mathrm{~cm}$ & $40 \mathrm{~cm}$ & Ort. & $20 \mathrm{~cm}$ & $40 \mathrm{~cm}$ & Ort. \\
\hline Kirazlı & & 7.7 & 178.0 & 177.9 & 185.0 & 185.0 & 185.0 & 181.3 & 181.5 & 181.4 \\
\hline Töre & & 2.7 & 192.3 & 192.5 & 195.0 & 196.0 & 195.5 & 193.8 & 194.2 & 194.0 \\
\hline Taşkent & & 9.7 & 188.7 & 189.2 & 197.0 & 198.0 & 197.5 & 193.3 & 193.3 & 193.3 \\
\hline Ort. & & 6.7 & 186.3 & 186.5 & 192.3 & 193.1 & 192.7 & 189.5 & 189.7 & \\
\hline LSD (\%5) & Y: 0.5 & Ç: 0.6 & SA: ö.d. & YxÇ: 0.9 & YxSA: 0.7 & ÇxSA: ö.d. & YxÇxSA: ö.d. & & & \\
\hline
\end{tabular}

\section{ARAŞTIRMA BULGULARI ve TARTIŞMA}

Olgunlaşma Gün Sayısı: Olgunlaşma gün sayısı değerlerine uygulanan istatistiki analiz sonuçları, yıl ve çeşit faktörleri ile yılxçeşit ve yılxsıra arası ikili interaksiyonlarının önemli olduğunu göstermiştir
(Çizelge 2). En kısa olgunlaşma gün sayısı değeri, denemenin ilk yılında Kirazlı çeşidinde 177.7 gün ile kaydedilmiş, en uzun sürede hasat olgunluğuna ulaşan çeşit ise denemenin ikinci yılında Taşkent çeşidi olmuştur (197.5 gün). Denemenin ilk yılındaki veriler 
incelendiğinde, tüm çeşitlerin daha erken dönemde hasat olgunluğuna ulaştığı kaydedilmiştir. Bu dönemin Mart-Nisan aylarındaki ortalama hava sıcaklığı ve toplam yağış değerlerinin, ikinci yıl ve çok yıllık ortalama değerlerinin üzerinde gerçekleşmesi nedeniyle, çeşitlerin çiçeklenmesi yaklaşık olarak 6-7 gün daha erken olmuştur. Denemenin ilk yılında, $20 \mathrm{~cm}$ ve $40 \mathrm{~cm}$ sıra arası mesafelerinde istatistiksel olarak önem taşımayan hasat olgunluğu değerleri kaydedilmiştir (sırasıyla; 186.7 gün ve 186.3 gün). Araştırmadan elde edilen sonuçlar, farklı sıra arası mesafelerinin yembezelyesinin olgunlaşma süresine önemli etkilerde bulunmadığını ortaya koymasına karşılık, bazı araştıııcılar (Jallow ve Ferguson, 1985; Sert ve Ikincikarakaya, 2011), bitki sıklığındaki artışın vejetasyon süresini kısalttığını bildirmektedirler. Hasat olgunluğuna ulaşma gün sayısı bakımından, çalışmamızda incelenen bezelye çeşitleri arasında önemli farklılıklar ortaya çıkmış ve bu durum, inceledikleri yembezelyesi çeşitlerinde olgunlaşma gün sayılarının 166-209 gün arasında değiştiğini ifade eden birçok araştııııının sonuçlarıyla uyumlu bulunmuştur (Sümerli vd., 2002; Sayar ve Anlarsal, 2007).

Hasattaki Bitki Sayısı (adet $/ \mathbf{m}^{2}$ ): Farklı sıra arası mesafelerinde yetiştirilen 3 farklı yembezelyesi çeşidinin hasattaki bitki sayılarına uygulanan istatistiki analiz sonuçlarına göre sadece sıra arası faktörü istatistiksel öneme sahip olmuştur (Çizelge 3). En yüksek bitki sayısı değeri 17.8 adet $/ \mathrm{m}^{2}$ ile $20 \mathrm{~cm}$ sıra arası mesafesinde kaydedilirken, $40 \mathrm{~cm}$ sıra arası mesafesinde yetiştirilen çeşitlerde bu sayı $12.5 \mathrm{adet} / \mathrm{m}^{2}$ olmuştur. Hasattaki bitki sayısına ilişkin bulgularımız; bezelye fidelerinin hayatta kalma oranı üzerinde atmosfer sıcaklığı ve toprak nemi değerlerinin doğrudan etkili olduğunu bildiren bazı araştırıcılar (Bilgili, 2009) yanında sıra arası mesafenin azalması ile birim alandaki bitki sayısının arttığını ifade eden araştırıcıların (Yılmaz, 1999; Alan ve Geren, 2012) bulgularıyla uyumlu gerçekleşmiştir.

Bitkide Bakla Sayısı: İstatistiki analiz sonuçları, bitkide bakla sayısı üzerine yıl, çeşit ve sıra arası gibi faktörler ile yıl $x$ çeşit ve sıra arası $x$ çeşit ikili interaksiyonlarının önemli etkilerde bulunduğunu göstermiştir (Çizelge 4). Bir bitkide en yüksek bakla sayısı, denemenin ikinci yılında Kirazlı çeşidinde 11.0 adet/bitki ile kaydedilmiş, en düşük değer ise denemenin ikinci yılında Töre çeşidinden alınmıştır (6.3 adet). En yüksek bakla sayısı $40 \mathrm{~cm}$ sıra arası mesafesinde yetiştirilen Kirazlı çeşidinden 10.2 adet/bitki ile elde edilirken, en düşük değer de 7.5 adet/bitki ile $20 \mathrm{~cm}$ sıra arası mesafesindeki Töre çeşidinden elde edilmiştir. Ahmed vd. (1999) ile Karakuş vd. (2005) sıra aralığının artması ile bitkideki bakla sayısının arttığını ortaya koyarken, Bozoğlu vd. (2004) ise Samsun koşullarında iki farklı bezelye çeşidi ile sürdürdükleri çalışmalarında, en yüksek bitkide bakla sayısı değerinin $40 \mathrm{~cm}$ 'den elde edildiğini, ancak $20 \mathrm{~cm}$ ve $30 \mathrm{~cm}$ sıra arası mesafelerinden kaydedilen değerlerin istatistiki olarak farklılık oluşturmadığını ifade etmişlerdir. Bu durum, dar sıra arası mesafesinde (20 $\mathrm{cm})$, metrekaredeki bitki sayısının artması ile bitkiler arasında, ışık, hava, su vb. ekolojik etmenlerden yararlanmada rekabetin arttığını ve dolayısıyla da, bakla sayılarının daha az olduğunu ve daha sınırlı geliştiklerini göstermektedir. Elde edilen değerler, Timurağaoğlu vd. (2004); Tan vd. (2012); Uzun vd. (2012)'nin bulguları ile uyum göstermektedir.

Çizelge 3. Farklı Sıra Arası Mesafelerinde Yetiştirilen Bazı Yembezelyesi Çeşitlerinin Metrekaredeki Bitki Sayıları (adet $/ \mathrm{m}^{2}$ )

Table 3. Number of plant per square meter of some forage pea cultivars grown at different row spacings (number $/ \mathrm{m}^{2}$ )

\begin{tabular}{lccccccccc}
\hline & \multicolumn{3}{c}{$\mathbf{2 0 1 3}$} & \multicolumn{3}{c}{$\mathbf{2 0 1 4}$} & \multicolumn{3}{c}{$\mathbf{2 0 1 3 - 2 0 1 4}$} \\
\hline Çeşitler & $\mathbf{2 0} \mathbf{~ c m}$ & $\mathbf{4 0} \mathbf{~ c m}$ & Ort. & $\mathbf{2 0} \mathbf{~ c m}$ & $\mathbf{4 0 ~} \mathbf{~ c m}$ & Ort. & $\mathbf{2 0} \mathbf{~ c m}$ & $\mathbf{4 0} \mathbf{~ c m}$ & Ort. \\
Kirazlı & 20.0 & 12.7 & 16.3 & 19.0 & 12.9 & 16.0 & 19.5 & 12.8 & 16.2 \\
Töre & 19.0 & 13.3 & 16.2 & 18.3 & 12.9 & 15.6 & 18.7 & 13.1 & 15.9 \\
Taşkent & 18.3 & 11.3 & 14.8 & 17.3 & 13.7 & 15.5 & 17.8 & 12.5 & 15.2 \\
\hline Ort. & 19.1 & 12.4 & 15.8 & 18.2 & 13.2 & 15.8 & 18.7 & 12.8 \\
\hline LSD (\%5) & Y: ö.d. & Ç: ö.d. & SA: 0.9 & YxÇ: ö.d. & YxSA: ö.d. & ÇxSA: ö.d. & YxÇxSA: ö.d. & & \\
\hline
\end{tabular}

Çizelge 4. Farkıı Sıra Arası Mesafelerinde Yetiştirilen Bazı Yembezelyesi Çeşitlerinin Bitkide Bakla Sayıları (adet/bakla)

Table 4. Number of pod per plant of some forage pea cultivars grown at different row spacings (number/pod)

\begin{tabular}{|c|c|c|c|c|c|c|c|c|c|}
\hline & \multicolumn{3}{|c|}{2013} & \multicolumn{3}{|c|}{2014} & \multicolumn{3}{|c|}{ 2013-2014 } \\
\hline Çeşitler & $20 \mathrm{~cm}$ & $40 \mathrm{~cm}$ & Ort. & $20 \mathrm{~cm}$ & $40 \mathrm{~cm}$ & Ort. & $20 \mathrm{~cm}$ & $40 \mathrm{~cm}$ & Ort. \\
\hline Kirazlı & 6.6 & 8.4 & 7.5 & 10.0 & 12.0 & 11.0 & 8.2 & 10.2 & 9.2 \\
\hline Töre & 5.9 & 6.6 & 6.3 & 9.0 & 11.1 & 10.0 & 7.5 & 8.9 & 8.2 \\
\hline Taşkent & 6.9 & 7.3 & 7.1 & 9.0 & 9.4 & 9.2 & 7.9 & 8.4 & 8.2 \\
\hline Ort. & 6.5 & 7.4 & 6.9 & 9.3 & 10.8 & 10.1 & 7.9 & 9.1 & \\
\hline LSD (\%5) & Ç: 0.5 & SA: 0.4 & YxÇ: 0.7 & YxSA: ö.d. & ÇxSA: 0.7 & YxÇxSA: ö.d. & & & \\
\hline
\end{tabular}


Baklada Tane Sayısı: Farklı sıra arası mesafelerinde yetiştirilen 3 farklı yembezelyesi çeşidinin baklada tane sayısı değerlerine uygulanan istatistiki analiz sonuçları, yıl, çeşit ve sıra arası faktörleri ile çeşitxsıra arası interaksiyonunun önemli etkilerde bulunduğunu göstermiştir (Çizelge 5). En yüksek baklada tane sayısı, $40 \mathrm{~cm}$ sıra arası mesafesinde yetiştirilen Kirazı ı çeşidinde 6.5 adet/bakla ile elde edilmiştir. Bilindiği gibi bitkide tane sayısı, bitkide bakla sayısı ile doğrudan ilişkili olmasının yanında, toprak, iklim ve bitki sıklığı etmenlerinden önemli derecede etkilenen bir karakterdir. Togay vd. (2006), yembezelyesi ekimlerinde metrekaredeki tohum sayısının arttırıması ile baklada tane sayısının azaldığını bildirmişler ve 20 tohum $/ \mathrm{m}^{2}$ ile yapılan ekimlerde ortalama 5.05 adet/bakla olan tane sayısının, 80 tohum $/ \mathrm{m}^{2}$ ekimlerinde 4.80 adet/ bakla'ya düştüğünü ifade etmişlerdir. Bakladaki tane sayısı değerleri değişik yıllarda farklı lokasyonlarda yürütülmüş olan çalışmalara paralel olarak, 3-6 adet/bakla arasında bulunmuştur (Timurağaoğlu vd. (2004); Tan vd. (2012); Uzun vd. (2012).

Tohum Verimi: İstatistik analiz sonuçları, yıl ve çeşit faktörlerinin tohum verimi üzerine önemli etkilerde bulunduğunu göstermiştir (Çizelge 6). En yüksek tohum verimi değeri ikinci yılda $210.4 \mathrm{~kg} / \mathrm{da}$ olarak kaydedilmiştir. Çeşitler arasında da Kirazlıçeşidi $310 \mathrm{~kg} / \mathrm{da} a^{\prime} \mathrm{lık}$ verim ile en üst sırada yer almıştır. Çalışmamızda, gerek 2013 yılında gerekse 2014 yılındaki hasatlarda bitki sayıları eşit sayıda kaydedilmiştir (Çizelge 3). Ancak, ikinci yıldaki veriler incelendiğinde bitkide bakla sayısı ve baklada tane sayısı gibi değerlerin yüksekliği ile tohum veriminde artış sağlanmıştır. Yapmış oldukları çalışmalarında elde ettikleri tohum veriminin $90-316 \mathrm{~kg} / \mathrm{da}$ arasında yer aldığını bildiren Toğay vd. (2006) ile Tan vd. (2012)'nin bulguları, çalışmamızdaki verim değerleri ile uyum içerisindedir.

Çizelge 5. Farklı Sıra Arası Mesafelerinde Yetiştirilen Bazı Yembezelyesi Çeşitlerinin Baklada Tane Sayıları (adet/bitki)

Table 5. Number of seed per pod of some forage pea cultivars grown at different row spacings (number/plant)

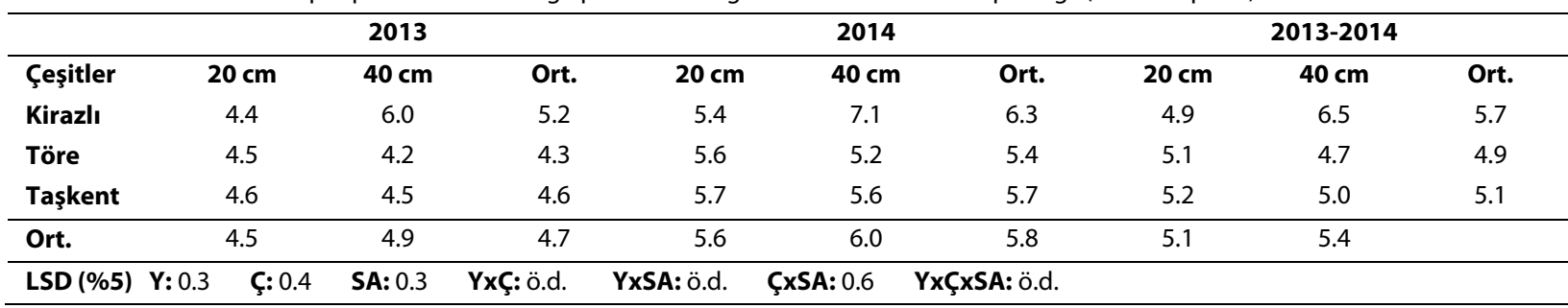

Çizelge 6. Farklı Sıra Arası Mesafelerinde Yetiştirilen Bazı Yembezelyesi Çeşitlerinin Tohum Verimleri (kg/da)

Table 6. Seed yields of some forage pea cultivars grown at different row spacings (kg/da)

\begin{tabular}{|c|c|c|c|c|c|c|c|c|c|c|}
\hline \multirow[b]{2}{*}{ Çeşitler } & \multicolumn{4}{|c|}{2013} & \multicolumn{3}{|c|}{2014} & \multicolumn{3}{|c|}{ 2013-2014 } \\
\hline & $20 \mathrm{~cm}$ & & $40 \mathrm{~cm}$ & Ort. & $20 \mathrm{~cm}$ & $40 \mathrm{~cm}$ & Ort. & $20 \mathrm{~cm}$ & $40 \mathrm{~cm}$ & Ort. \\
\hline Kirazlı & 272.5 & & 270.8 & 271.7 & 350.5 & 345.4 & 348.0 & 311.5 & 308.1 & 309.8 \\
\hline Töre & 93.0 & & 86.7 & 90.0 & 104.2 & 98.4 & 101.3 & 98.6 & 92.5 & 95.6 \\
\hline Taşkent & 127.4 & & 108.4 & 117.9 & 202.4 & 161.4 & 181.9 & 164.9 & 134.9 & 149.9 \\
\hline Ort. & 164.3 & & 155.3 & 159.8 & 219.0 & 201.7 & 210.4 & 191.7 & 178.5 & \\
\hline LSD (\%5) & Y: 27.4 & Ç: 33.6 & SA: ö.d. & YxÇ: ö.d. & YxSA: ö.d. & ÇxSA: ö.d. & YxÇxSA: ö.d. & & & \\
\hline
\end{tabular}

Bin Dane Ağırlığı: Bin dane ağırlığı değerine uygulanan istatistiki analiz sonuçları, yıl ve çeşit faktörlerinin istatistiki olarak önemli olduklarını ortaya koymuştur (Çizelge 7). Denemenin ikinci yılındaki ortalama bin tane ağırlığı değeri (120.3 g), ilk yıldan (113.7 g) daha yüksek bulunmuştur. Denemenin ikinci yılında kaydedilen ve özellikle bitkinin dane doldurma dönemine denk gelen süreçteki dönemsel sıcaklık ve yağış değerlerinin yüksekliği dikkat çekicidir (Çizelge 1). Bu dönemde çeşitlerin fotosentez sonucu oluşturdukları yedek besin maddelerini taneye aktarımlarının tam olduğu ve artan fotosentetik aktiviteyle de bin tane ağırlıklarının yükseldiği düşünülebilir. Örneğin Alan ve Geren (2012) de, birim alandaki yüksek bitki sayısı, dal sayısı, bakla sayısı vb. unsurların bin dane ağırlığı üzerine özellikle etkili olduğunu bildirmektedirler. Çeşitler içerisinde de Kirazlı çeşidi $156.7 \mathrm{~g}$ ile ilk sırada yer almıştır. Farklı ekolojik koşullarda farklı yembezelyesi genotipleri ile sürdürdükleri çalışmalarında, bin tane ağırlığının 110$440 \mathrm{~g}$ arasında olduğunu ifade eden bazı araştırıcıların bulguları (Sayar ve Anlarsal, 2007; Uzun vd., 2012) sonuçlarımızı destekler niteliktedir. 
Çizelge 7. Farklı Sıra Arası Mesafelerinde Yetiştirilen Bazı Yembezelyesi Çeşitlerinin Bin Dane Ağırıkları (g)

Table 7. Thousand kernel weights of some forage pea cultivars grown at different row spacings $(\mathrm{g})$

\begin{tabular}{|c|c|c|c|c|c|c|c|c|c|}
\hline & \multicolumn{3}{|c|}{2013} & \multicolumn{3}{|c|}{2014} & \multicolumn{3}{|c|}{ 2013-2014 } \\
\hline Çeşitler & $20 \mathrm{~cm}$ & $40 \mathrm{~cm}$ & Ort. & $20 \mathrm{~cm}$ & $40 \mathrm{~cm}$ & Ort. & $20 \mathrm{~cm}$ & $40 \mathrm{~cm}$ & Ort. \\
\hline Kirazlı & 147.3 & 150.3 & 148.8 & 155.0 & 162.0 & 158.5 & 151.2 & 156.2 & 153.7 \\
\hline Töre & 95.3 & 91.0 & 93.2 & 101.0 & 97.0 & 99.0 & 98.2 & 94.0 & 96.1 \\
\hline Taşkent & 104.7 & 93.7 & 99.2 & 108.0 & 99.0 & 103.5 & 106.3 & 96.3 & 101.3 \\
\hline Ort. & 115.8 & 111.7 & 113.7 & 121.3 & 119.3 & 120.3 & 118.6 & 115.5 & \\
\hline LSD (\%5) & Y: 5.3 Ç: 6.5 & SA: ö.d. & YxÇ: ö.d. & YxSA: ö.d. & ÇxSA: ö.d. & YxÇxSA: ö.d. & & & \\
\hline
\end{tabular}

\section{SONUÇ}

Akdeniz ikliminin egemen olduğu İzmir'in Bornova ilçesinde iki yıl süreyle yürütülen çalışmamızda yembezelyesi çeşitlerinin bölge koşullarındaki tohum üretim potansiyellerine etki eden bazı etmenler incelenmiştir. Çiftlik hayvanlarının yoğun yem ihtiyaçlarını gidermek amacıyla kullanılabilecek seçenekler arasında yer alan baklagillerden biri olan yembezelyesi çeşitlerinin bölgedeki performanslarına bakıldığında, özellikle Kirazlı çeşidinin, dane veriminin üstün nitelikte olduğu görülmüştür. Farklı bitki sıklıklarının farklı yembezelyesi çeşitlerinin üzerindeki etkisi ise özellikle verim bakımından önemli bir farklılık oluşturmadığı, sadece $20 \mathrm{~cm}$ sıra arası mesafesinde rakamsal olarak daha yüksek verim değerlerinin oluştuğu saptanmıştır.

\section{KAYNAKLAR}

Açıkgöz, N. 1993. Tarımda Araştırma ve Deneme Metodları (III. Basım). Ege Üniversitesi Ziraat Fakültesi Yayınları No:478. Ege Üniversitesi Ziraat Fakültesi Ofset Atölyesi, Bornova-İzmir, 202s.

Ahmed, C.M.S, F. Mahmood and M.A. Khokhor. 1999. Evaluation of some yield components of pea (Pisum sativum) cultivars under Islamabad conditions. Sarhad Journal of Agriculture 15 (4) 291-293.

Alan, Ö. ve H. Geren. 2012. Bezelye'de (Pisum sativum L.) Farklı Ekim Zamanlarının Tane Verimi ve Diğer Bazı Tarımsal Özellikler Üzerine Etkisi. Ege Üniversitesi Ziraat Fakültesi Dergisi, 49(2), S: 127-134.

Anonim, 2015. Bornova Bölge Meteoroloji İstasyonu, Bornovaİzmir.

Bilgili,U. 2009. Yem Bezelyesi (Pisum arvense L.), Cilt:II, Tarım ve Köyişleri Bakanlığı TÜGEM, İzmir, s:440-447.

Bozoğlu, H., E. Pekşen ve A. Gülümser. 2004. Sıra Aralığı ve Humat Uygulamasının Bezelyenin Verim ve Bazı Özelliklerine Etkisi. Tarım Bilimleri Dergisi, 10 (1), s: 53-58.

Jallow, A.T. and T.U. Ferguson. 1985. Effects on planting density and cultivar of seed yield of cowpeas (Vigna unguiculata (L.) Walp.) in Trinidad. Tropical Agriculture, St. Augustine, 62(2): 121-124.

Karakuş, M., V. Çiftçi, Y. Toğay ve N. Toğay. 2005. Van-Gevaş Koşullarında Farklı Sıra Aralıklarının Fasulye (Phaseolus vulgaris L.) de Verim ve Bazı Verim Öğelerine Etkisi, Yüzüncü Yıl Üniversitesi Ziraat Fakültesi, Tarım Bilimleri Dergisi, 15(1): $57-62$

Sayar, M.S. ve A.E. Anlarsal. 2007. Diyarbakır Ekolojik Koşullarında Bazı Yembezelyesi (Pisumarvense L.) Hat ve Çeşitlerinin Verim ve Verim Öğelerinin Belirlenmesi Üzerine Bir Araştırma. Çukurova Üniversitesi Fen Bilimleri Enstitüsü, Yüksek Lisans Tezi, 53s.
Sert, H. ve S. İkincikarakaya. 2011. Hatay İli Ekolojik Şartlarında Börülce (Vigna sinensis (L.) Savi) Çeşitlerinin Tane Verimi ve Bazı Tarımsal Özellikleri Üzerine Farklı Bitki Sıklıklarının Etkisi. Selçuk Üniversitesi Fen Bilimleri Enstitüsü, Yüksek Lisans Tezi, 45s.

Sümerli, M., İ. Gül ve Y. Yılmaz. 2002. Diyarbakır Ekolojik Şartlarında Yembezelyesi Hatlarının Verim ve Verim Öğelerinin Belirlenmesi. Güneydoğu Anadolu Tarımsal Araştırma Enst. Md. Gelişme Raporları (Yayınlanmamış). Diyarbakır.

Tan, M., A. Koç ve Z. Dumlu Gül. 2012. Morphological Characteristics and Seed Yield of East Anatolian Local Forage Pea Ecotypes. Turkish Journal of Field Crops, 17(1), s: 24-30.

Timurağaoğlu, K.A, A. Genç ve S. Altınok. 2004. Ankara Koşullarında Yem Bezelyesi Hatlarında Yem ve Tane Verimleri. Tarım Bilimleri Dergisi, 10(4), s: 457-461.

TUIK, 2015. www.tuik.gov.tr (erişim tarihi: 26.01.2015).

Toğay, N., Y. Toğay, M. Erman ve B. Yıldırım. 2006. Kışlık İki Bezelye Hattı (Pisum sativum ssp. arvense L.)'nda Farklı Bitki Sıklıklarının Bazı Tarımsal Özellikler Üzerine Etkisi. Yüzüncü Yll Üniversitesi, Ziraat Fakültesi, Tarım Bilimleri Dergisi, 16(2): 97-103.

Uzun, A., H. Gün ve E. Açıkgöz. 2012. Farklı Gelişme Dönemlerinde Biçilen Bazı Yem Bezelyesi (Pisum sativum L.) Çeşitlerinin Ot, Tohum ve Ham Protein Verimlerinin Belirlenmesi. Uludağ Üniv. Ziraat Fakültesi Dergisi, 26 (1), s: 27-38.

Yılmaz, H.A. 1999. Kahramanmaraş Ekolojisinde Farklı Ekim Sıklıklarının, İki Soya (Gliycine max (L.) Merill) Çeşitinde, Verim ve Verim Unsurlarına Etkisi, Turkish Journal of Agriculture and Forestry, 23, s:223-232. 